\title{
MANAGEMENT OF ENDOCRINE DISEASE Flushing: current concepts
}

\section{Isabel Huguet ${ }^{1}$ and Ashley Grossman ${ }^{2}$}

'Department of Endocrinology, Hospital de la Princesa, Madrid, Spain and ${ }^{2}$ Department of Endocrinology, Oxford Centre for Diabetes, Endocrinology and Metabolism, University of Oxford, and NET Centre of Excellence, Royal Free London, UK
Correspondence

should be addressed

to I Huguet

Email

inm.huguet@gmail.com

\begin{abstract}
Objective: Flushing can be defined as a sensation of warmth accompanied by erythema that most commonly is seen on the face and which occurs in episodic attacks. Such a problem can be clinically problematic, since many conditions and drugs can be related to flushing, and while often there appears to be no underlying organic disease, it is important to exclude disorders since they may be life-threatening conditions.

Design and methods: We performed a search in MEDLINE using the terms 'flushing' in combination with 'carcinoid syndrome', 'pheochromocytoma', 'mastocytosis', 'menopausal hot flush' and 'treatment'. European and American guidelines relating to neuroendocrine tumours, mastocytosis and menopause were reviewed.

Results: In this review, we discuss the main causes of flushing and propose an algorithm based on pathogenesis, which can be used to guide the clinical evaluation process. We also review recent significant developments in the assessment and treatment of the carcinoid syndrome and menopausal hot flushes, which should guide the clinical practice regarding this common but sometimes confusing condition.

Conclusions: When evaluating flushing, a precise systematic approach is needed to exclude potentially serious underlying causes, although despite this, the cause of the disorder is not always found. If symptoms are not progressive, the patient should be advised about its apparently benign nature in order to avoid unnecessary studies or initiating treatments of minimal benefit.
\end{abstract}

\section{Introduction}

Flushing can be defined as a sensation of warmth accompanied by erythema that most commonly occurs on the face, but may also involve the neck, ears, chest, epigastrium, arms or other areas. Flushing characteristically occurs in episodic attacks contrasting with the persistent erythema of photosensitivity, erythema multiforme or sunburn, and in carcinoid syndrome, flushing may result in telangiectasias.

Epidemiologically, the data are difficult to report due to the large variety of conditions and drugs related to flushing. Around 80\% (1) of post-menopausal women experience hot flushes, and a similar syndrome is seen in more than $65 \%$ of men with prostatic cancer during treatment with medical or surgical castration (2),
두 2017 European Society of Endocrinology Printed in Great Britain being the most common complaint reported by men undergoing androgen suppression treatment (3). Flushing is also included in the manifestations of the carcinoid syndrome, occurring in $20-30 \%$ of patients with midgut neuroendocrine tumours (NETs).

Flushing is not an uncommon presenting symptom to endocrinologists, but as such is generally not well covered in endocrine texts. In our experience, its presence may cause on-going uncertainty in the physician and continuing anxiety in the patient. Recently, consensus statements on post-menopausal flushing have been published, and novel therapies devised for the treatment of carcinoid-induced flushing. In this article, we aim to review the pathogenesis and main aetiologies of flushing,

Published by Bioscientifica Ltd. 
emphasising the principal differences between them, and to survey the latest developments in the treatment of this heterogeneous and challenging condition, and suggest investigative pathways.

\section{Search strategy}

We performed a search in MEDLINE, with no specific data range. The used terms were 'flushing' in combination with 'carcinoid syndrome', 'pheochromocytoma', 'mastocytosis', 'menopausal hot flush' and 'treatment'. European and American guidelines related to neuroendocrine tumours, mastocytosis and menopause were also reviewed. We also searched the reference lists of articles identified by this search strategy and selected those we judged relevant.

\section{Pathogenesis}

Flushing is the visual consequence of increased cutaneous blood flow secondary to vasodilatation, and the predilection for specific anatomical areas seems to be related to the volume of visible superficial vessels and, possibly, a qualitative difference in facial cutaneous vascular response to systemic agents and neuronal control.

Flushing can be classified according to the presence or absence of associated sweating, since the physiopathology differs between them: on the one hand, neurally mediated flushing is frequently associated with sweating ('wet flushing') due to the concomitant neurological control of autonomic nerve fibres of vascular smooth muscle and eccrine sweat glands (4) (Fig. 1) leading to flushing,

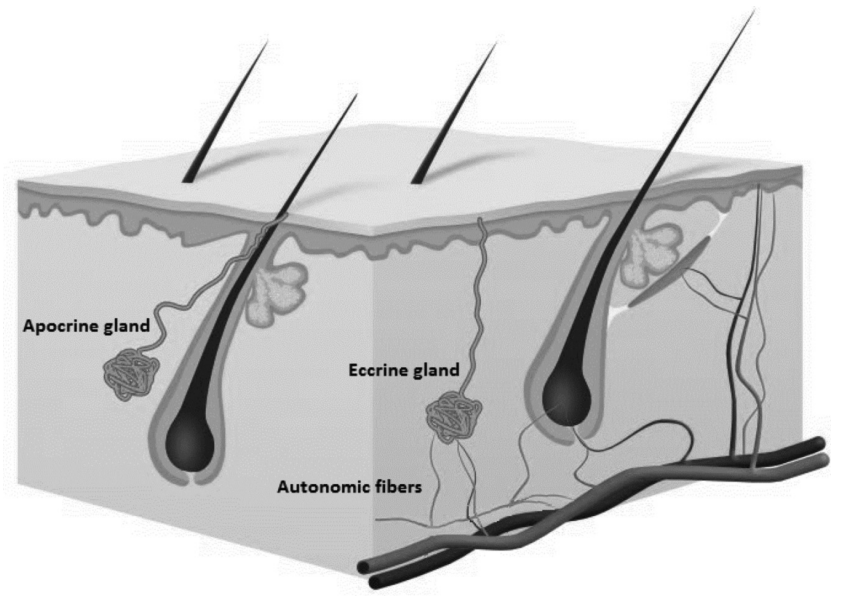

Figure 1

Autonomic innervation of eccrine gland. which can be the result of events at both peripheral and central sites. On the other hand, isolated ('dry') flushing is mainly due to the action of circulating vasodilator substances such as kinins, prostaglandins, vasoactive intestinal peptide (VIP), calcitonin gene-related peptide, serotonin (5-HT) and histamine. Of these mediators, serotonin is worthy of special mention due to its involvement in the carcinoid syndrome. Serotonin causes very complex and variable cardiovascular responses that include bradycardia or tachycardia, hypotension or hypertension and vasodilatation or vasoconstriction. This wide variety of responses has been explained by the presence of different receptors (5-HT1, 5-HT2, 5-HT3, 5-HT4, 5-HT5A/5B and 5-HT7) of which 5-HT2A, 5-HT2B and 5-HT7 are present in vascular smooth muscle. 5-HT7 leads to vascular relaxation, opposite to 5-HT2, and when both types of receptor are present in vessels the ultimate response to 5-HT depends upon the pre-existing vascular tone, the level of 5HT and the proportions in which the two receptors types are distributed (5).

\section{Aetiology (based on the presence/absence of sweating)}

\section{Neural mechanism: wet flushing}

The most common autonomic neural-mediated flushing reactions are thermoregulatory, both normal physiological responses and inappropriate varieties. A second major category comprises those associated with emotions. Disturbances of this autonomic system frequently occur at both extremes of life. In early life, there appears to be instability of this system in response to stress, so-called 'blushing'. Darwin studied blushing and described it as an entirely involuntary expression, which cannot be consciously inhibited, occurring in all 'races' and in blind people, and suggested an inherited tendency to excessive blushing. While it usually improves with age, in some cases, blushing may impair quality of life and dominate social interactions, leading patients to seek medical help.

Later in life, abrupt withdrawal of oestrogens in women leads to menopausal flushing. Classic menopausal vasomotor symptoms (VMS) include hot flushes and night sweats. As noted above, around $80 \%$ of post-menopausal women experience hot flushes and sleep complaints are reported by $40-60 \%$ (5); epidemiological studies have found that, despite the number of episodes decreasing over time, the duration of this period could be up to 5-13 years, with the longest duration in African-American women (1). The perception of the experiences related to 
the menopause and the quality of life during this period are very influenced by personality, culture, education, social support and the ability to confront difficult situations. In an attempt to study the heterogeneity of temporal patterns of VMS, Tepple et al. evaluated 1455 women with nonsurgical menopause over a median follow-up of 15.4 years and described four distinct trajectories: 'early onset' (onset about 11 years before the final menstrual period with decline after menopause), 'late onset' (onset near the final menstrual period with later decline), 'high frequency' (onset early with persistently high frequency) and 'low frequency' (persistently low frequency). In a further analysis, they found that relative to women with a persistently low frequency of VMS, women with persistently high- and early-onset VMS had a more adverse psychosocial and health profile (6). Of course, this begs the question as to what is cause and effect.

Despite extensive studies, the pathogenesis of menopausal hot flushes remains unclear. Initially, high circulating concentrations of gonadotrophins were thought to be involved in the development of menopausal flushing, but since it has also been described to occur after total hypophysectomy (7) and in Sheehan syndrome (8), this concept appears to be inadequate. Currently, it is accepted that oestrogens play a major role in the maintenance of core temperature (9), and there is little doubt that they - or their absence - are involved in the initiation of menopausal hot flushes. It seems that it is not the absolute level of oestrogens, but the rate of oestrogen withdrawal that determines the onset of flushes (10). Despite the fact that the mechanism is not entirely understood, it is known that oestrogens have complex interactions with the noradrenergic system $(11,12)$ since noradrenaline plays a major role in thermoregulation, acting in part through central $\alpha_{2}$-adrenergic (13) receptors; modulation of brain adrenergic receptors by oestrogen $(11,12)$ could be one of the main mechanisms involved in the onset of flushing. This theory is supported by the fact that the $\alpha_{2}$-adrenoceptor agonist clonidine has some beneficial effects in the control of menopausal flushing.

A classic study showed a decrease in menopausal flushes in women infused with the opiate-antagonist naloxone, possibly indicating the involvement of a dynorphin pathway (14), while more recently, hypothalamic kisspeptin/neurokinin B/dynorphin (KNDy) neurons have been related to the physiology of 'menopausal' flushes. Post-menopausal women have been shown to demonstrate hypertrophy of these neurons in the hypothalamic arcuate nucleus, changes that have also been demonstrated in young monkeys after ovariectomy and reversed by oestrogen replacement (15). Animal models have studied the connections between KNDy neurons and the pathways that control heat-defence effectors involving the preoptic structures (16) and have also evaluated the thermoregulatory effects of ablating KNDy neurons, indicating that KNDy neurons facilitate cutaneous vasodilatation, an important heat dissipation effector (17). Based on these previous investigations, Prage et al. very recently reported a randomised doubleblind placebo-controlled trial, using an oral neurokinin 3 receptor antagonist (MLE4901). Using an oral dose of $40 \mathrm{mgbd}$, they were able to show a significant reduction in the mean number and severity of hot flushes leading to an improvement in psychosocial and physical symptoms. The authors concluded that this finding may open a new treatment modality, which could potentially transform the lives of women severely affected by hot flushes without the possible risks of being exposed to oestrogen (18).

In a parallel way, there is a gradual reduction of the male sex hormone with increasing age, mainly due to testis dysfunction (Leydig cell mass reduction as well as reduced testicular circulation), but also partially to reduced testosterone-stimulating hormones (19). This condition usually has an insidious onset with the slow progression of symptoms such as sexual dysfunction, weakness, insomnia, mood disorders and reduction of bone density. In contrast, when the androgen deficiency occurs in a sudden manner as in androgen deprivation therapy for prostate cancer patients, symptoms tend to be more severe, and hot flushes can be described, not only as the more frequent symptom, but also in up to $27 \%$ of patients report hot flushes as being the most troublesome side effect of treatment. After bilateral orchidectomy, about $50 \%$ of patients develop hot flushes occurring within a few months; remarkably, when castration is caused by GnRH analogues, the incidence of hot flushes is higher, around $60-70 \%(20)$.

Neurological diseases in the central nervous system (CNS) can also cause disturbances of autonomic function. Tumours and other lesions affecting the walls of the third ventricle, such as diencephalic epilepsy, can activate the autonomic centres residing in its walls. Peripherally, a misdirection of regenerated parasympathetic nerve fibres after parotid surgery or injury, perinatal birth injury or facial trauma in childhood, can lead to recurrent episodes of gustatory flushing and/or sweating in the cutaneous distribution of the auriculotemporal nerve, known as Frey syndrome.

Although flushing can occur in the natural course of Parkinsonism, it is the use of dopamine agonists that 
has generally been accompanied by flushing in these patients (21).

\section{Dry flushing}

Several drugs have been reported to cause flushing, and a wide variety of mechanisms are involved (Table 1). Occasionally, flushing as a side effect can be seen as frequently as in $90 \%$ of patients in the case of nicotinic acid, even necessitating the discontinuation of treatment.

Some circulating substances secreted by tumours can also induce flushing as one of the principal clinic manifestations of the neoplasia. Flushing is included as one of the skin manifestations in the carcinoid syndrome, along with diarrhoea, being present in $20-30 \%$ of patients with midgut neuroendocrine tumours. This syndrome usually affects patients with neuroendocrine tumours arising from the midgut with liver metastases since serotonin is secreted into the portal venous system and, in the absence of metastases, it would be inactivated by the liver and would not reach the systemic circulation.

Table 1 Drugs related to flushing.

\begin{tabular}{|c|c|}
\hline Mechanism & Drugs \\
\hline Vasodilatation & $\begin{array}{l}\text { - Nitroglycerine, } \\
\text { nitro-derivatives } \\
\text { - Phosphodiesterase-5 } \\
\text { inhibitors } \\
\text { - Calcium channel blockers } \\
\text { (mainly dihydropyridine) } \\
\text { - Calcitonin } \\
\text { - Cholinergic drugs }\end{array}$ \\
\hline Increased prostacyclins & $\begin{array}{l}\text { - Prostaglandins D2, E } \\
\text { - Non-steroidal anti- } \\
\text { inflammatory drugs }\end{array}$ \\
\hline Direct activation of TRPV-1 & - Nicotinic acid \\
\hline Release of vasoactive mediators & $\begin{array}{l}\text { - Vancomycin, Rifampicin } \\
\text { (histamine) } \\
\text { - Cyclosporine } \\
\text { (endothelin-1 and } \\
\text { nitric oxide) Cisplatin, } \\
\text { Dacarbazine } \\
\text { - TRH } \\
\text { - Bromocriptine } \\
\text { - Morphine and opioids } \\
\text { (histamine) }\end{array}$ \\
\hline Other/unknown mechanism & $\begin{array}{l}\text { - Triamcinolone } \\
\text { - Catecholamines } \\
\text { - Radiological contrast } \\
\text { agents } \\
\text { - Metoclopramide } \\
\text { - Isofluranes, Fentanyl } \\
\text { - Serotonin reuptake } \\
\text { inhibitors (can cause } \\
\text { night sweats by blocking } \\
\text { muscarinic receptors) }\end{array}$ \\
\hline
\end{tabular}

However, there are some particular cases in which flushing can appear in the absence of liver metastases, as is the case of ovarian carcinoids or peritoneal seeding of gastrointestinal tumours $(22,23)$, since serotonin can directly reach the systemic circulation in these cases.

Four types of carcinoid flushing have been described in the literature: erythematous, violaceous, prolonged and bright red. The erythematous flush is usually associated with midgut carcinoids but the ileum, as part of the midgut, seems to show a patchier and more violaceus flush. Foregut tumours (stomach, lung and pancreas) are said to be associated with a bright-red 'geographic' flush. Bronchopulmonary carcinoids are associated with more prolonged flushing, lasting several hours to some days (Bouloux MP, Sweating and Flushing: Evaluation and Management. 2013 Meet The Professor: Endocrine Case Management. http://dx.doi.org/10.1210/ MTP2.9781936704637.ch39). In the carcinoid syndrome, most flushes occur spontaneously, but they can also be provoked by certain foods rich in serotonin (chocolate, nuts, avocado, banana and red wine), alcohol, palpation of the liver and general anaesthesia.

Phaeochromocytomas are tumours arising from neural crest-derived chromaffin cells of the adrenal medulla and sympathetic ganglia (the latter being referred to as paragangliomas). There is increasing interest in these tumours since their pathogenesis and progression are very strongly influenced by genetics. A germline mutation in one of the susceptibility genes identified to date explains $\sim 40 \%$ of all cases (24). Despite being described in most textbooks as a significant symptom of these disorders, flushing as a manifestation of phaeochromocytoma is in fact infrequent. In general, the $\alpha_{1}$-mediated vasoconstriction of cutaneous vessels is the dominant feature of the paroxysms seen with secretory phaeochromocytomas and paragangliomas. Nevertheless, while flushing is a rare and unexpected consequence of secretory phaeochromocytomas, there are scattered case reports that suggest it can occur, albeit infrequently. The mechanism for such rare flushing in phaeochromocytoma remains unclear: it could be due to a rebound vasodilatation of the facial cutaneous blood vessels after the classical spell of pallor and sweating. Other possible mechanism may include blood pressure lability generated by prolonged exposure to catecholamines. In addition, some phaeochromocytomas may produce other flushing mediators, such as calcitonin gene-related peptide, vasoactive intestinal polypeptide or adrenomedullin. Another endocrine tumour that may secrete bioactive substances is medullary thyroid 
carcinoma, which, in addition to calcitonin, has the potential to cause clinical symptoms such as sweating and flushing by substances including biogenic amines, ACTH, $\mathrm{CRH}$ and prostaglandins. Curiously, renal cell carcinoma also can rarely cause flushing, which it is felt may be due to the production of gonadotrophin-like hormones by the tumour (25).

The term mastocytosis refers to a heterogeneous group of clonal disorders characterised by the proliferation and accumulation of mast cells in various tissues, including the skin and the bone narrow. Depending on the organs involved, mastocytosis is divided into cutaneous mastocytosis (affecting mainly children), systemic mastocytosis and localised mast cell tumours (26). In the adult-onset form, there is usually systemic involvement, and such findings increase in extent and severity over time (26). The symptoms in mastocytosis are likely due to the release of mast cell mediators such as histamine, prostaglandin D2, leukotrienes, cytokines and chemokines, but also to mast cell infiltration of tissues (e.g. osteolytic lesions, hepatomegaly and impaired liver function or malabsorption due to gastrointestinal mast cell infiltration). Flushing is one of the clinical features related to the release of mast cell mediators along with pruritus, nausea, diarrhoea, abdominal pain and vasodilatory shock, any of which may occur spontaneously or be induced by triggers.

In many situations, despite intensive investigation, no objective cause can be found to explain the flushing, leading to the diagnosis of idiopathic flushing. Despite the benign nature of this disorder, these patients often undergo repeated evaluations in attempt to diagnose a disease associated with flushing and may receive medications that are of minimal benefit and which can even be damaging. In an exhaustive study, Friedman et al. (27) extensively evaluated ten patients with recurrent idiopathic flushing. After a complete clinical and laboratory assessment that included observation of attacks by physicians and a psychiatric evaluation, they found an apparent exaggerated description of the attacks given by the patients with normal levels of histamine and routine laboratory tests. In this study, there was a high percentage of underlying psychiatric abnormalities, with somatisation disorder being the most prevalent and being diagnosed in almost every patient.

\section{Diagnosis: proposed algorithm}

A careful and detailed history is mandatory. The first step will be to differentiate between dry or wet flushing. This initial stage is not always obvious since in some patients with dry flushes, this is associated with significant anxiety, which can be a confounder. An exhaustive drug history and an evaluation of precipitating factors and associated symptomatology should initially guide the study. Patients with flushing secondary to hypogonadism tend to have night sweats as the predominant aspect. NETs can also manifest secretory diarrhoea and often have a past history of a diagnosis of irritable bowel syndrome (Fig. 2).

Physical examination of the skin can also contribute to the initial clinical suspicion: urticaria pigmentosa and excoriated lesions caused by scratching would suggest mastocytosis, while the presence of the dermatologic manifestations of pellagra can appear in patients with neuroendocrine tumours due to the deficiency of tryptophan (which can be used to synthesise niacin).

If the patient has dry flushes, the carcinoid syndrome has to be ruled out. The major investigations in suspected cases are 24-h urinary 5-hydroxyindole acetic acid (5-HIAA) and plasma chromogranin A ( $\mathrm{CgA})$. Serotonin released by carcinoid tumours is metabolised by monoamine oxidases in the liver, lungs and brain to 5-HIAA. In the presence of a carcinoid syndrome, the overall sensitivity and specificity of urinary 5-HIAA is of the order of 70 and $90 \%$, respectively (28). Falsely, low 5-HIAA levels may be encountered in patients with renal impairment and those on haemodialysis. In addition, 5-HIAA may be increased

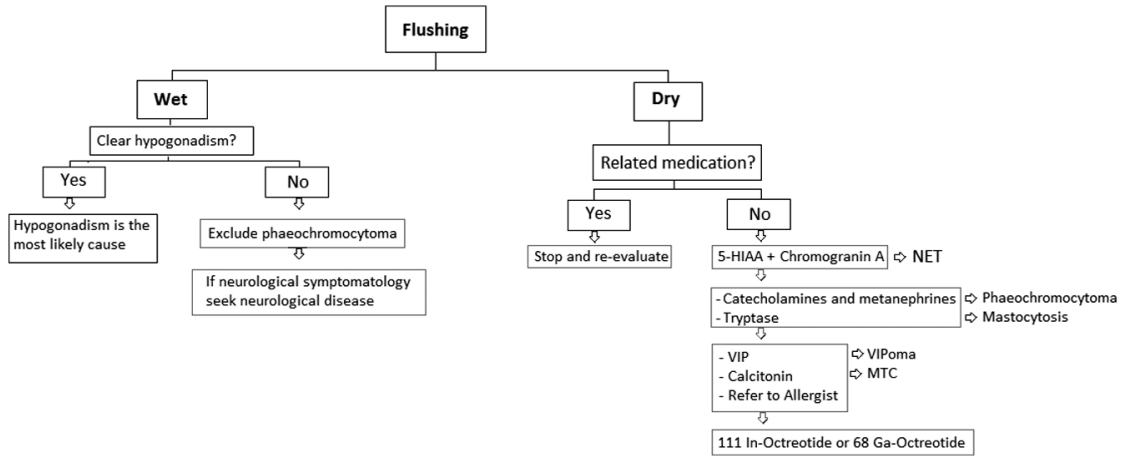

\section{Figure 2}

Proposed algorithm for the evaluation of flushing. 
in untreated patients with malabsorption who may have increased urinary tryptophan metabolites. Such patients include those with coeliac disease (gluten-sensitive enteropathy), tropical sprue, Whipple disease, intestinal stasis and cystic fibrosis (chronic intestinal obstruction) (28). The patient should be provided with careful dietary instructions, since strict food and drug precautions are necessary in order to prevent false positives (avoiding during five days prior to the test: avocados, bananas, plums, kiwifruit, melons, pineapple, coffee and tomatoes, as well as nasal drops and sprays, tricyclic antidepressants and monoamine oxidase inhibitors, salicylates, L-dopa and phenothiazines). Since collecting a 24 -h urine specimen may be difficult for patients, new strategies are being developed, such as measurement of 5-HIAA in spot-urine sample or assessing plasma levels. Correlations between 24-h and a 'spot' urine sample (normalised to creatinine) were assessed by Calanchini et al., by pairing 130 samples from 108 patients. In their results, a spot-urine was concordant with 24 -h urine results in $85 \%$, suggesting that the spot-urine is a simple and promising sample type for 5-HIAA analysis, in particular for follow-up in patients with known elevated 5-HIAA level (29). Another strategy is the measurement of plasma fasting 5-HIAA values. Tellez et al. compared 24-h urine 5-HIAA values against plasma 5 -HIAA values in patients with NETs. They found that in a group of 115 patients with all types of NETS, in a subset of patients with midgut NET and in a subgroup of midgut NETS with liver metastasis, the correlation between the urine and fasting plasma 5-HIAA values was statistically significant $(P \leq 0.0001)(30)$. However, further studies are necessary in order to refine these promising tests.

While urinary 5HIAA remains the definitive test for flushing secondary to a carcinoid syndrome, CgA is probably the most valuable marker in the diagnosis and follow-up of NETs. An elevated CgA was found to be more sensitive than high urinary 5-HIAA levels in patients with metastatic midgut lesions (87 vs $76 \%$ respectively) (31). The specificity of CgA in the diagnosis of NETs depends on the tumour type and burden. In clinical practice, the most common causes of false-positive results are the use of proton pump inhibitors and cases of atrophic gastritis. Lack of gastric acid leads to hypergastrinaemia due to loss of negative feedback for gastrin, and this chronic elevation of gastrin levels provoke hyperplasia of the neuroendocrine cells of the stomach, which are able to secrete CgA (32). Proton pump inhibitor (PPI) therapy may increase $\mathrm{CgA}$ concentration just five days after first intake, so this drug should be discontinued at least 14 days before the test (33), and possibly 3 weeks is the safest. However, this should always be considered in the context of patients with a high likelihood of a gastrinoma in which case such omission of therapy may be life-threatening. Histamine type-2 receptor antagonists may also have an effect on the increase of the marker, and it is suggested to discontinue these medications for at least $24 \mathrm{~h}$ before the scheduled $\mathrm{CgA}$ examination. Other causes of false-positive results are impaired kidney function due to reduced renal clearance, while inflammatory bowel disease can also cause falsepositive results. Approximately 50\% of patients with inflammatory bowel diseases tend to have an elevated $\mathrm{CgA}$, especially during the active phase of the disease. $\mathrm{CgA}$ should be determined in fasting individuals since food can induce increased levels in healthy individuals.

When a carcinoid syndrome has been excluded, two major disease entities have to be considered: systemic mastocytosis and phaeochromocytoma. The total tryptase level in serum or plasma seems to be a more discriminating biomarker than urinary methylhistamine for the diagnosis of systemic mastocytosis. In general, total tryptase levels are greater than $20 \mathrm{ng} / \mathrm{mL}$ in patients with systemic mastocytosis, being recognised as a minor criterion in the diagnostic evaluation of systemic mastocytosis by the World Health Organization (Table 2). However, lower tryptase levels can be seen in patients with cutaneous mastocytosis, monoclonal mast cell activation syndrome and systemic mastocytosis

Table 2 WHO diagnostic criteria for systemic mastocytosis.

WHO diagnostic criteria for systemic mastocytosis

Requires one major + one minor criterion or three minor Major criterion Multifocal, dense aggregates of mast cells (15 or more) detected in sections of bone marrow and/or other extracutaneous organ(s)

Minor criterion a. In biopsy section, more than $25 \%$ of the masts cells in the infiltrate have atypical morphology, or, of all the mast cells in the aspirate smear, more than $25 \%$ are immature or atypical

b. Mast cells in BM, blood or other extracutaneous organ express CD2 and/or CD25 in addition to normal mast cell markers

c. Detection of KIT point mutation at codon 816 in bone marrow, blood, or other extracutaneous organs

d. Serum total tryptase persistently $>20 \mathrm{ng} / \mathrm{mL}$ (not a valid criteria in cases of systemic mastocytosis with associated clonal haematologic non-mast-cell lineage disease) 
with limited bone marrow involvement (34). On the other hand, the diagnosis of phaeochromocytoma depends on biochemical evidence of catecholamine production by the tumour. Adrenal chromaffin cells produce catecholamines, which are metabolised to metanephrines by membrane-bound catecholamineO-methyltransferase. While catecholamines can be directly measured, metanephrines are a much more reliable test since they are continuously produced within tumours by a process that is independent of exocytotic catecholamine release (35). Lenders et al. evaluated several biochemical tests in a multicentre study including 800 patients and concluded that sensitivities of plasma free metanephrines and urinary fractionated metanephrines were higher than those for plasma catecholamines and urinary catecholamines (99, 97, 84 and $86 \%$ respectively); they also determined that combining different tests did not improve the diagnostic yield beyond that of a single test of plasma free metanephrines (36).

If this work-up is unrevealing, other less frequent conditions such as medullary thyroid carcinoma, VIPoma and renal carcinoma should also be considered. If attacks persist and no cause can be found, then a radiolabelled ${ }^{111}$ In-octreotide or (preferably) a ${ }^{68} \mathrm{Ga}$-octreotate-PET scan should reveal any occult tumour, but this is rarely positive in the absence of abnormal cross-sectional imaging (CT/MR) as flushing patients usually have obvious disease. In a systematic review and metaanalysis, Deppen et al. evaluated the limited published literature directly comparing ${ }^{111}$ In-DTPA-octreotide with ${ }^{68} \mathrm{Ga}$-DOTATATE imaging. In their conclusions, they found a superiority of ${ }^{68} \mathrm{Ga}$-DOTATATE PET/CT for the diagnosis or reassessment of tumours with high somatostatin receptor expression (37). The available evidence also supports ${ }^{68} \mathrm{Ga}$-DOTATATE imaging, which often demonstrates tumour uptake in some patients with negative or equivocal ${ }^{111}$ In-DTPA-octreotide scans (38). Additionally, ${ }^{68} \mathrm{Ga}$-DOTATATE PET/CT provides a lower effective radiation dose (39) and superior image quality compared to ${ }^{111}$ In-DTPA-octreotide imaging and is more convenient for patients.

In many patients, no cause is ever found: Friedman (26) suggests that patients should be re-examined every 6-12 months to determine whether symptoms are progressive, thus requiring further study. If symptoms are not progressive, the patient may be spared needless studies. A psychiatric consultation may be considered in the presence of persistent but non-progressive symptoms in the absence of proven organic disease.

\section{Treatment}

\section{Menopausal hot flushes}

Classically, hormone replacement treatment (HRT) has been the gold standard treatment for menopausal hot flushes; however, this treatment is not exempt from risks, and should not be the first option in women with a high cardiovascular risk, increased risk of venous thromboembolism (with a probable lower risk with transdermal therapy $(0.05 \mathrm{mg}$ twice weekly or lower $)$ compared to oral therapy) (40) or breast cancer. According to new guidelines developed for the treatment of symptoms during the menopause (41), if no contraindications are present, the choice of initiating a HRT should be a shared decision-making approach based on the woman's risks and treatment goals, and the decision to continue HRT should be revisited at least annually, targeting the shortest total duration of the treatment (41). If vasomotor symptoms remain persistent and intolerable, these guidelines propose a switch in the mode of administration of HRT or to adjust the dose of oestrogen and/or progestogen. The duration of treatment should be consistent with the treatment goals of the individual, and the benefit/risk profile needs to be individually reassessed annually (40). Other causes of flushing should be considered if after treatment adjustment, no changes are evident.

For women seeking pharmacological management for moderate-to-severe vasomotor symptoms for whom HRT is contraindicated, or who choose not to take it, the initial choice should be the use of selective serotonin or serotonin-noradrenaline reuptake inhibitors (41), since several studies have demonstrated a reduction of hot flushes scores by $60 \%(42,43)$. Not only frequency is reduced, but also the severity and bother, and not only in depressed or anxious women (44), with venlafaxine and paroxetine the most effective (45). Caution is advised in the use of paroxetine in patients receiving treatment for breast cancer since it markedly interferes with the metabolism of tamoxifen.

Despite the fact that the mechanism remains unclear, gabapentin or pregabalin have also been used to ameliorate hot flushes when there are no contraindications. If vasomotor symptoms are not responding or these nonhormonal prescription therapies are not tolerated, a trial of clonidine is suggested, since this $\alpha_{2}$-adrenergic receptor agonist reduces brain noradrenaline, decreasing the rate of hot flushes occurrence by $46 \%$ (46).

A small number of head-to-head studies have compared varying oestrogen doses and preparations 
with non-hormonal agents $(47,48)$, the limited available evidence suggesting that standard dose hormone replace treatment is more effective than other treatments but the significance of the small magnitude between them is of uncertain clinical relevance. It should be kept in mind that there is a strong, consistently reported placebo effect, which averages 30\% and occurs more often in women with high anxiety and stress scores. Finally, as noted above, the introduction of NK3 antagonists is likely to play a major role in the treatment of menopausal hot flushes in the future.

\section{Carcinoid syndrome}

Patients with flushing due to carcinoid syndrome have greatly benefited from long-acting somatostatin analogues. In 1978, it was first reported that a somatostatin analogue was able to prevent spontaneous and provoked flushing in patients with carcinoid tumours (49). This treatment significantly reduces plasma CgA levels, especially in patients with classical midgut NETs, probably reflecting an inhibition of both hormone synthesis and release from the tumour cells. Studies on long-acting analogues demonstrate a symptomatic response rate of $70 \%$ (50) in patients with the carcinoid syndrome, and referring specifically to flushing, a response rate of $50-60 \%(51,52)$. Since the goal of improving symptom control is a common reason for somatostatin analogue dose escalation, Strosberg et al. have recently evaluated the effects of above-standard dose of octreotide LAR in a multicentre study, concluding that the resolution or improvement of flushing after dose escalation can be observed in $80 \%$ of patients (53). When no symptomatic control is achieved, another option of treatment would be the novel multireceptor-targeted somatostatin analogue pasireotide (previously known as SOM230). In a recently published phase II, open-label, multicentre study of pasireotide in patients with advanced NET whose symptoms of carcinoid syndrome (diarrhoea/flushing) were inadequately controlled by octreotide LAR, pasireotide 600-900 $\mu \mathrm{g}$ given subcutaneously reduced daily flushing episodes from $4.9 \pm 4.1$ at baseline to $1.0 \pm 0.8$ post-treatment and was effective in controlling the symptoms of diarrhoea and flushing in $27 \%$ of patients with advanced NETs who were no longer responsive to octreotide LAR (54). The use of octreotide before invasive procedures is also important to prevent a carcinoid crisis. According to Öberg et al., in patients in whom symptoms are well controlled by octreotide LAR $20-30 \mathrm{mg}$, a supplementary bolus dose of 250-500 $\mu$ g octreotide should be given subcutaneously within one to two hours before the procedure. For emergency surgery in therapy-naïve patients with functional NETs, a 500-1000 $\mathrm{\mu g}$ intravenous bolus of octreotide or $500 \mu \mathrm{g}$ subcutaneously should be given one to two hours before the procedure. The recommended intra-operative use of octreotide for carcinoid crisis with hypotension is bolus intravenous doses of $500-1000 \mu \mathrm{g}$, with treatment repetition at five-minute intervals until control of symptoms is achieved. Alternatively, following an intravenous bolus dose, continuous intravenous infusion of octreotide at a dose of 50-200 $\mu$ g per hour may be given. In any patient who has required supplemental dosing during a procedure, the post-operative dose would be $50-200 \mu \mathrm{g}$ per hour for $24 \mathrm{~h}$, followed by resumption of the preoperative treatment schedule (55). Somatostatin analogues can also be radiolabelled with ${ }^{90} \mathrm{Y}$ or ${ }^{177} \mathrm{Lu}$ and be used in the treatment of inoperable or metastatic neuroendocrine tumours, producing disease-control rates of $68-94 \%$ (56). In addition, biochemical and symptomatic responses are commonly observed.

Clinical experience indicates that patients on somatostatin analogues may develop tachyphylaxis or may respond less well to somatostatin due to an increase in tumour burden, so new options are being developed. Tryptophan hydroxylase (TPH) is the rate-limiting enzyme in serotonin synthesis. It converts tryptophan to 5-hydroxytryptophan, which is subsequently converted to serotonin. Telotristat ethyl is a novel molecule that inhibits tryptophan hydroxylase. In a single-arm multicentre study, patients experienced substantial reductions in bowel symptoms and in urinary 5-HIAA, and a modest, but statistically significant, decrease from baseline in the number of episodes of flushing, showing a reduction of $27 \%$ from a baseline of 2.78 episodes per day $(P=0.04)(57)$. In an international randomised, double-blind, placebo-controlled phase III study in 135 patients with carcinoid syndrome whose diarrhoea (>four bowel movements per day) was not adequately controlled on somatostatin analogue therapy, treatment with telotristat $(250 \mathrm{mg}$ or $500 \mathrm{mg}$ three times per day, or placebo) markedly decreased urinary 5-HIAA suggesting effective TPH inhibition. In this study, bowel movements were also significantly reduced, from 5.8 to 3.8 per day on telotristat ethyl $500 \mathrm{mg}$ three times a day (tds), while flushing episodes diminished by 0.16 per day on placebo, 0.3 per day on telotristat $250 \mathrm{mg}$ tds and by 0.53 per day on telotristat ethyl $500 \mathrm{mg}$ tds. The latter trend was not statistically significant, but the trial baseline flushing rate was relatively low and the study was principally designed to explore the effects on diarrhoea (58). This may 
also indicate that while there may be an element of the flushing mediated by $5 \mathrm{HT}$, other agents may also be involved.

Thus, carcinoid flushing is generally responsive to somatostatin analogues, and in general, the long-acting analogues octreotide LAR and lanreotide autogel are preferred; for patients not fully responsive, an abovestandard dose trial can be performed, and pasireotide may be another effective option, although currently its licence is for the treatment of Cushing's disease. Telotristat ethyl is a novel agent, which is yet to become licensed, but may represent an additional useful tool in the armamentarium.

\section{Mastocytosis}

For patients with mastocytosis, there is no specific therapy currently available but several advances in the understanding of this disease are being developed. Abdulkadir et al. (59) observed that over 90\% of the patients carry the D816V point mutation that renders the c-KIT receptor constitutively active. The histone deacetylase inhibitors SAHA epigenetically silences c-KIT followed by major mast cell apoptosis, with a correlation between cell death and systemic mastocytosis disease severity, with cell death more pronounced in the case of aggressive disease. In another study, midostaurin, an inhibitor of tyrosine kinases, has shown to target c-KIT mutants associated with mastocytosis and seems to reduce the risk of death, so indeed new targeted therapies are being developed for the treatment of this condition (60). In specific relation to flushing, this is often treated with an $\mathrm{H}_{1}$-histaminereceptor antagonist such as hydroxyzine or non-sedating antihistamines such as cetirizine or fexofenadine, with expert opinion endorsing the daytime use of non-sedating antihistamines and nighttime use of sedating ones (61).

\section{Conclusions}

Flushing is a challenging symptom and several serious diseases can be the cause of this condition. A careful clinical history is required in order to guide $t$ biochemical and radiological studies, and when the cause is elucidated, specific targeted therapy is available in some situations, but unfortunately not for every disease. Not uncommonly, the cause is not found, leading to the diagnosis of idiopathic flushing. In this situation, if symptoms are not progressive, avoiding needless investigations and treatments with minimal benefit - such as antihistamines or steroids - should be the priority.
Declaration of interest

The authors declare that there is no conflict of interest that could be perceived as prejudicing the impartiality of this review.

\section{Funding}

This research did not receive any specific grant from any funding agency in the public, commercial or not-for-profit sector.

\section{References}

1 Avis NE, Crawford SL, Greendale G, Bromberger JT, EversonRose SA, Gold EB, Hess R, Joffe H, Kravitz HM, Tepper PG et al. Duration of menopausal vasomotor symptoms over the menopause transition. JAMA Internal Medicine 2015175 531-539. (doi:10.1001/ jamainternmed.2014.8063)

2 Karling P, Hammar M \& Varenhorst E. Prevalence and duration of hot flushes after surgical or medical castration in men with prostatic carcinoma. Journal of Urology 1994152 1170-1173.

3 Irani J, Salomon L, Oba R, Bouchard P \& Mottet N. Efficacy of venlafaxine, medroxyprogesterone acetate, and cyproterone acetate for the treatment of vasomotor hot flushes in men taking gonadotropin-releasing hormone analogues for prostate cancer: a double-blind, randomised trial. Lancet Oncology 201011 147-154. (doi:10.1016/S1470-2045(09)70338-9)

4 Uno H. Sympathetic innervation of the sweat glands and piloarrector muscles of macaques and human beings. Journal of Investigative Dermatology 197769 112-120. (doi:10.1111/1523-1747.ep12497915)

5 Cintron D, Lipford M, Larrea-Mantilla L, Spencer-Bonilla G, Lloyd R, Gionfriddo MR, Gunjal S, Farrell AM, Miller VM \& Murad MH. Efficacy of menopausal hormone therapy on sleep quality: systematic review and meta-analysis. Endocrine 201755 702. (doi:10.1007/ s12020-016-1072-9)

6 Tepper PG, Brooks MM, Randolph JF Jr, Crawford SL, Khoudary SM, Gold EB, Lasley BL, Jones B, Joffe H, Hess R et al. Characterizing the trajectories of vasomotor symptoms across the menopausal transition. Menopause 201623 1067-1074. (doi:10.1097/ GME.0000000000000676)

7 Mulley G, Mitchell JRA \& Tattersall RB. Hot flushes after hypophysectomy. BMJ 19772 1062. (doi:10.1136/bmj.2.6094.1062)

8 Zarate A. Frontiers of Hormone Research, vol 2. Basel: Karger, 1973.

9 Tankersley CG, Nicholas WC, Deaver DR, Mikita D \& Kenney WL. Estrogen replacement in middle-aged women: thermoregulatory responses to exercise in the heat. Journal of Applied Physiology (1985) 199273 1238-1245.

10 Kronenberg F. Menopausal hot flashes: a review of physiology and biosociocultural perspective on methods of assessment. Journal of Nutrition 2010140 1380S-1385S. (doi:10.3945/jn.109.120840)

11 Etgen AM, Ansonoff MA \& Quesada A. Mechanism of ovarian steroid regulation of norepinephrine receptor-mediated signal transduction in the hypothalamus: implications for female reproductive physiology. Hormones and Behavior 200140 169-170. (doi:10.1006/ hbeh.2001.1676)

12 Ansonoff MA \& Etgen AM. Receptor phosporilation mediates estradiol reduction of alpha 2-adrenoceptor coupling to $\mathrm{G}$ protein in the hypothalamus of female rats. Endocrine 200114 165-174. (doi:10.1385/ENDO:14:2:165)

13 Goldberg M \& Robertson D. Yohimbine: a pharmacologic probe for study of $\alpha 2$-adrenoceptor. Pharmacological Reviews 198335 143-180.

14 Lightman SL, Jacobs HS, Maguire AK, McGarrick G \& Jeffcoate SL. Climacteric flushing: clinical and endocrine response to infusion of naloxone. British Journal of Obstetrics and Gynaecology $1981 \mathbf{8 8}$ 919-124. (doi:10.1111/j.1471-0528.1981.tb02229.x) 
15 Rometo AM, Krajewski SJ, Voytko ML \& Rance NE. Hypertrophy and increased kisspeptin gene expression in the hypothalamic infundibular nucleus of postmenopausal women and ovariectomized monkeys. Journal of Clinical Endocrinology and Metabolism 200792 2744-2750. (doi:10.1210/jc.2007-0553)

16 Rance NE, Dacks PA, Mittelman-Smith MA, Romanovsky AA \& Krajewski-Halla SJ. Modulation of body temperature and LH secretion by hypothalamic KNDy (kisspeptin, neurokinin B and dynorphin) neurons: a novel hypothesis on the mechanism of hot flushes. Frontiers in Neuroendocrinology 201334 211-227. (doi:10.1016/j. yfrne.2013.07.003)

17 Mittelman-Smith MA, Williams H, Krajewski-Hall SJ, McMullen NT \& Rance NE. Role for kisspeptin/neurokinin B/dynorphin (KNDy) neurons in cutaneous vasodilatation and the estrogen modulation of body temperature. PNAS 2012109 19846-19851. (doi:10.1073/ pnas.1211517109)

18 Prage JK, Roberts RE, Comninos AN, Clarke S, Jayasena CN, Nash Z, Doyle C, Papadopoulou DA, Bloom SR, Mohideen P et al. Neurokinin 3 receptor antagonism as a novel treatment for menopausal hot flushes: a phase 2, randomised, double-blind, placebo controlled trial. Lancet 2017389 1809-1820. (doi:10.1016/S0140-6736(17)30823-1)

19 Neaves WB, Johnson L, Porter JC, Parker CR Jr \& Petty CS. Leydig cell numbers, daily sperm production, and serum gonadotropin levels in aging men. Journal of Clinical Endocrinology and Metabolism 198459 756-763. (doi:10.1210/jcem-59-4-756)

20 Kouriefs C, Georgiou M \& Ravi R. Hot flushes and prostate cancer: pathogenesis and treatment. BJU International 200289 379-383. (doi:10.1046/j.1464-4096.2001.01761.x)

21 Calne DB, Teychenne PF, Claveria LE, Eastman R, Greenacre JK \& Petri A. Bromocriptine in parkinsonism. BMJ 1974 4 442-444. (doi:10.1136/bmj.4.5942.442)

22 Simões-Pereira J, Wang LM, Kardos A \& Grossman A. Carcinoid syndrome and carcinoid heart disease as manifestations of nonmetastatic ovarian carcinoid tumour. Acta Medica Portuguesa 2017 30 421-425.

23 Feldman JM \& Jones RS. Carcinoid syndrome from gastrointestinal carcinoids without liver metastasis. Annals of Surgery 1982196 33-37. (doi:10.1097/00000658-198207000-00008)

24 Favier J, Amar L \& Gimenez-Roqueplo AP. Paraganglioma and phaeochromocytoma: from genetics to personalized medicine. Nature Reviews Endocrinology 201511 101-111. (doi:10.1038/ nrendo.2014.188)

25 Cronin RE, Kaehny WD, Miller PD, Stables DP, Gabow PA, Ostroy PR \& Schrier R. Renal cell carcinoma: unusual systemic manifestations. Medicine 197655 291-311. (doi:10.1097/00005792-197607000-00002)

26 Valent P, Aberer E, Beham-Schmid C, Fellingers C, Fuch W, Gleixner $\mathrm{KV}$, Greul R, Hadzijusufovic E, Hoermann G, Sperr WR et al. Guidelines and diagnostic algorithm for patients with suspected systemic mastocytosis: a proposal of the Austrian competence network (AUCNM). American Journal of Blood Research 20133 174-180.

27 Friedman BS, Germano P, Miletti J \& Metcalfe DD. A clinicopathologic study of ten patients with recurrent unexplained flushing. Journal of Allergy and Clinical Immunology 199493 53-60. (doi:10.1016/00916749(94)90232-1)

28 O'Toole D, Grossman A, Gross D, Delle Fave G, Barkmanova J, O'Connor J, Pape U \& Plöckinger U. ENETS consensus guidelines for the standards of care in neuroendocrine tumors: biochemical markers. Neuroendocrinology 200990 194-202.

29 Calanchini M, Tadman M, Krogh J, Fabbri A, Grossman A \& Shine B. Measurement of urinary 5-hydroxyindole acetic acid: correlation between spot versus 24-hour urine collection. Endocrine Abstracts 2016 46 P4. (doi:10.1530/endoabs.46.P4)

30 Tellez MR, Mamikunian G, O'Dorisio TM, Vinik AI \& Woltering EA. A single fasting plasma 5-HIAA value correlates with 24-hour urinary 5 -HIAA values and other biomarkers in midgut neuroendocrine tumors (NETs). Pancreas 201342 405-410. (doi:10.1097/ MPA.0b013e318271c0d5)

31 Janson ET, Holmberg L, Stridsberg M, Eriksson B, Theodorsson E, Wilander E \& Öberg K. Carcinoid tumors: analysis of prognostic factors and survival in 301 patients from a referral center. Annals of Oncology 19978 685-690. (doi:10.1023/A:1008215730767)

32 D'Adda T, Corleto V, Pilato FP, Baggi MT, Robutti F, Delle Fave G \& Bordi C. Quantitative ultrastructure of endocrine cells of oxyntic mucosa in Zollinger-Ellison syndrome. Correspondence with light microscopic findings. Gastroenterology 199099 17-26. (doi:10.1016/0016-5085(90)91224-t)

33 Mosli HH, Dennis A, Kocha W, Asher LJ \& Van Uum SHM. Effect of short-term proton pump inhibitor treatment and its discontinuation on chromogranin A in healthy subjects. Journal of Clinical Endocrinology and Metabolism 201297 E1731-E1735. (doi:10.1210/ jc.2012-1548)

34 Akin C, Valent P \& Metcalfe DD. Mast cell activation syndrome: proposed diagnostic criteria. Journal of Allergy and Clinical Immunology 2010126 1099.e4-1104.e4. (doi:10.1016/j.jaci.2010.08.035)

35 Lenders JWM, Duh QY, Eisenhofer G, Gimenez-Roqueplo AP, Grebe SKG, Murad MH, Naruse M, Pacak K \& Young WF Pheochromocytoma and paraganglioma: an Endocrine Society Clinical Practice Guideline. Journal of Clinical Endocrinology and Metabolism 201499 1915-1942. (doi:10.1210/jc.2014-1498)

36 Lenders JW, Pacak K, Walther MM, Linehan WM, Mannelli M, Friberg P \& Eisenhofer G. Biochemical diagnosis of pheochromocytoma: which test is best? JAMA 2002287 1427-1434.

37 Deppen SA, Blume J, Bobbey AJ, Blume J, Bobey AJ, Shah C, Graham MM, Lee P, Delbeke D \& Walker RC. 68Ga-DOTATATE compared with 111In-DTPA-Octreotide and conventional imaging for pulmonary and gastroenteropancreatic neuroendocrine tumors: a systematic review and meta-analysis. Journal of Nuclear Medicine 201657 872-878. (doi:10.2967/jnumed.115.165803)

38 Kwekkeboom DJ, de Herder WW, Kam BL, Van Eijck CH, Van Essen M, Kooij PP, Feelders RA, Van Aken M \& Krenning EP. Treatment with the radiolabeled somatostatin analog [177 Lu-DOTA 0, Tyr3] octreotate: toxicity, efficacy, and survival. Journal of Clinical Oncology 200826 2124-2130. (doi:10.1200/JCO.2007.15.2553)

39 Walker RC, Smith GT, Liu E, Moore B, Clanton J \& Stabin M. Measured human dosimetry of 68Ga-DOTATATE. Journal of Nuclear Medicine 201354 855-860. (doi:10.2967/jnumed.112.114165)

40 de Villiers TJ, Hall JE, Pinkerton JV, Cerdas Pérez S, Rees M, Yang C \& Pierroz DD. Revised global consensus statement on menopausal hormone therapy. Climacteric 201619 313-315.

41 Stuenkel CA, Davis SR, Gompel A, Lumsden MA, Murad MH, Pinkerton JV \& Santen RJ. Treatment of symptoms of the menopause: an Endocrine Society clinical practice guideline. Journal of Clinical Endocrinology and Metabolism 2015100 3975-4011. (doi:10.1210/ jc.2015-2236)

42 Stearns V, Beebe KL, Iyengar M \& Dube E. Paroxetine controlled release in the treatment of menopasual hot flushes: a randomized controlled trial. JAMA 2003289 2827-2834. (doi:10.1001/ jama.289.21.2827)

43 Loprinzi CL, Kugler JW, Sloan JA, Mailliard JA, LaVasseur BI, Barton DL, Novotny PJ, Dakhil SR, Rodger K, Rummans TA et al. Venlafaxine in the management of hot flushes in survivors of breast cancer: a randomized controlled trial. Lancet 2000356 2059-2063. (doi:10.1016/S0140-6736(00)03403-6)

44 Freeman EW, Guthrie KA, Caan B, Sternfeld B, Cohen LS, Joffe H, Carpenter JS, Anderson GL, Larson JC, Ensrud KE et al. Efficacy of escitalopram for hot flashes in healthy menopausal women: a randomized controlled trial. JAMA 2011305 267-274. (doi:10.1001/ jama.2010.2016)

45 Loprinzi CL, Sloan J, Stearns V, Slack R, Ivengar M, Diekmann B, Kimmick G, Lovato J, Gordon PM, Pandya K et al. Newer antidepressants and gabapentin for hot flashes: an individual patient 
pooled analysis. Journal of Clinical Oncology 200927 2831-2837. (doi:10.1200/JCO.2008.19.6253)

46 Laufer LR, Erlik Y, Meldrum DR \& Judd HL. Effect of clonidine on hot flashes in postmenopausal women. Obstetrics and Gynecology 198260 $583-586$.

47 Joffe H, Guthrie KA, LaCroix AZ, Reed SD, Ensrud KE, Manson JE, Newton KM, Freeman EW, Anderson GL, Larson JC et al. Low-dose estradiol and the serotonin-norepinephrine reuptake inhibitor venlafaxine for vasomotor symptoms: a randomized clinical trial. JAMA Internal Medicine 2014174 1058-1066. (doi:10.1001/ jamainternmed.2014.1891)

48 Aguirre W, Chedraui P, Mendoza J \& Ruilova I. Gabapentin vs lowdose transdermal estradiol for treating post-menopausal women with moderate to very severe hot flushes. Gynecological Endocrinology 2010 26 333-337. (doi:10.3109/09513590903511539)

49 Thulin L, Samnegard H, Tyden G, Long DH \& Efendic S. Efficacy of somatostatin in a patient with carcinoid syndrome. Lancet 1978243. (doi:10.1016/S0140-6736(78)91348-X)

50 Modlin IM, Pavel M, Kidd M \& Gustafsson BI. Review article: somatostatin analogues in the treatment of gastroenteropancreatic neuroendocrine (carcinoid) tumours. Alimentary Pharmacology and Therapeutics 201031 169-188.

51 Wolin EM, Fisher GA, Kunz PL, Liyanage N, Lowenthal SP, Mirakhur B, Pommier RF, Shaheen M \& Vinik A. Efficacy of lanreotide autogel/depot (LAN) vs placebo (PBO) for symptomatic control of carcinoid syndrome (CS) in neuroendocrine tumor (NET) patients from the ELECT study E.M. Annals of Oncology 201627 (Supplement 6) 438P. (doi:10.1093/annonc/mdw369.23)

52 Ruszniewski P, Ish-Shalom S, Wymenga M, O'Toole D, Arnold R, Tomassetti P, Bax N, Caplin M, Eriksson B, Glaser B et al. Rapid and sustained relief from the symptoms of carcinoid syndrome: results from an open 6-month study of the 28-day prolonged-release formulation of lanreotide. Neuroendocrinology $200480244-251$. (doi:10.1159/000082875)

53 Strosberg JR, Benson AB, Huynh L, Duh MS, Goldman J, Rademaker AW \& Kulke M. Clinical benefits of above-standard dose of octreotide LAR in patients with neuroendocrine tumors for control of carcinoid syndrome symptoms: a multicenter retrospective chart review study. Oncologist 201419 930-936. (doi:10.1634/ theoncologist.2014-0120)

54 Kvols LK, Oberg KE, O'Dorisio TM, Mohideen P, de Herder WW, Arnold R, Hu K, Zhang Y, Hughes G, Anthony L et al. Pasireotide (SOM230) shows efficacy and tolerability in the treatment of patients with advanced neuroendocrine tumors refractory or resistant to octreotide LAR: results from a phase II study. Endocrine-Related Cancer 201219 657-666. (doi:10.1530/ERC-11-0367)

55 Öberg K, Kvols L, Caplin M, Delle Fave G, de Herder W, Rindi G, Ruszniewski P, Woltering EA \& Wiedenmann B. Consensus report on the use of somatostatin analogs for the management of neuroendocrine tumors of the gastroenteropancreatic system. Annals of Oncology 200415 966-973.

56 Bodei L, Kwekkeboom DJ, Kidd M, Modlin IM \& Krenning EP. Radiolabeled somatostatin analogue therapy of gastroenteropancreatic cancer. Seminars in Nuclear Medicine 201646 225-238. (doi:10.1053/j. semnuclmed.2015.12.003)

57 Pavel M, Hörsch D, Caplin M, Ramage J, Seufferlein T, Phillip Banks JV, Lapuerta P, Sands A, Zambrowicz B, Fleming D et al. Telotristat etiprate for carcinoid syndrome: a single-arm, multicenter trial. Journal of Clinical Endocrinology and Metabolism 2015100 1511-1519. (doi:10.1210/jc.2014-2247)

58 Kulke MH, Horsch D, Caplin ME, Anthony LB, Bergsland E, Öberg $\mathrm{K}$, Welin S, Warner RRP, Lombard-Bohas C, Kunz PL et al. Telotristat ethyl, a tryptophan hydroxylase inhibitor for the treatment of carcinoid syndrome. Journal of Clinical Oncology 201635 14-23. (doi:10.1200/jco.2016.69.2780)

59 Abdulkadir H, Grootens J, Kjellander M, Lindberg EH, Nilsson G \& Ungerstedt J. Histone deacetylase inhibitor SAHA mediates epigenetic silencing of KIT D816V mutated systemic mastocytosis primary mast cells and selective apoptosis of mutated mast cells. Blood 20151262834 .

60 Chandesris MO, Damaj G, Canioni D, Brouzes C, Lhermitte l, Hanssens K, Frenzel L, Cherquaoui Z, Durieu I, Durupt S et al. Midostaurin in advanced systemic mastocytosis. New England Journal of Medicine 2016374 2605-2606. (doi:10.1056/NEJMc1515403)

61 Cardet JC, Akin C \& Lee MJ. Mastocytosis: update on pharmacotherapy and future directions. Expert Opinion on Pharmacotherapy 201314 2033-2045. (doi:10.1517/14656566.2013.824424)

Received 24 April 2017

Revised version received 16 May 2017

Accepted 31 May 2017 